\title{
Analysis on the Light-Scattering Effect in Dye-Sensitized Solar Cell according to the $\mathrm{TiO}_{2}$ Structural Differences
}

\author{
Min-Kyu Son, ${ }^{1}$ Hyunwoong Seo, ${ }^{2,3}$ Soo-Kyoung Kim, ${ }^{1}$ Na-Yeong Hong, ${ }^{1}$ \\ Byung-Man Kim, ${ }^{1}$ Songyi Park, ${ }^{1}$ Kandasamy Prabakar, ${ }^{1}$ and Hee-Je Kim ${ }^{1}$ \\ ${ }^{1}$ Department of Electrical Engineering, Pusan National University, San 30, Jangjeon-Dong, Geumjeong-Gu, \\ Busan 609-735, Republic of Korea \\ ${ }^{2}$ Graduate School of Information Science and Electrical Engineering, Kyushu University, 744 Motooka, Nishi-ku, \\ Fukuoka 819-0395, Japan \\ ${ }^{3}$ Center of Plasma Nano-Interface Engineering, Kyushu University, 744 Motooka, Nishi-ku, Fukuoka 819-0395, Japan
}

Correspondence should be addressed to Hee-Je Kim, heeje@pusan.ac.kr

Received 10 September 2012; Accepted 15 October 2012

Academic Editor: Yuexiang Li

Copyright (c) 2012 Min-Kyu Son et al. This is an open access article distributed under the Creative Commons Attribution License, which permits unrestricted use, distribution, and reproduction in any medium, provided the original work is properly cited.

\begin{abstract}
A light-scattering layer is widely used in highly efficient dye-sensitized solar cells (DSCs) because it improves the light-harvesting ability of a DSC by reflecting the light passing through the transparent $\mathrm{TiO}_{2}$ layer. Among many parameters affecting this lightscattering effect, the thickness of the $\mathrm{TiO}_{2}$ photoelectrode is also a significant parameter. However, most studies regarding the influence of the $\mathrm{TiO}_{2}$ photoelectrode thickness on the light-scattering effect have only focused on the thickness of the transparent $\mathrm{TiO}_{2}$ layer and have ignored the light-scattering layer thickness itself. Therefore, in this study, we analyzed the light scattering effect according to the thickness of the light-scattering layer and the resulting photovoltaic performance of the DSC. Finally, it was confirmed that the light-scattering effect is enhanced to some degree with the increase of the light-scattering layer thickness, while it is weakened when the light-scattering layer thickness is further increased.
\end{abstract}

\section{Introduction}

Dye-sensitized solar cells (DSCs) have attracted much attention as a promising alternative to conventional silicon solar cells due to their low cost, simple fabrication process, and their various applications to such things as flexible devices and building integrated photovoltaic systems [1-3]. Generally, a DSC is a photoelectrochemical solar cell made up of a dye-sensitized nanocrystalline $\mathrm{TiO}_{2}$ photo-electrode, a Pt deposited counter-electrode used for the catalyst of the iodide/triiodide $\left(\mathrm{I}^{-} / \mathrm{I}_{3}{ }^{-}\right)$redox system, and an electrolyte [4]. In this type of solar cell, the amount of light captured by the dye-sensitized $\mathrm{TiO}_{2}$ photoelectrode has a strong influence on the overall performance because the electrons are generated directly from the excited dye molecules by the irradiated sunlight $[5,6]$. There have been many efforts to improve the performances by increasing the amount of light captured in the DSC such as developments in where the sensitizers have wider adsorption spectra [7-10], the introduction of a tandem structure [11-13], and the use of the light-scattering effect.

Among these improvements, the light-scattering effect has drawn much attention since it is a simple method for enhancing the light absorption. The basic concept of lightscattering effect was introduced by Usami in 1997 [14]. He suggested a new photoelectrode structure, which uses an overlayer made up of a large particle semiconductor film on top of a layer made up of a small particle semiconductor film; the light scattered by the overlayer caused an increase in the light absorption. In early days, many studies have been focused on the evaluation of the light-scattering effect in the DSC by using various simulation methods based on the Mie theory [15], the Monte Carlo model [16], and the many-flux model [17]. Since then, the light-scattering effect has been widely used as an essential technique to improve the DSC performance. There are many structures and materials that have been used for the light-scattering effect: large particle $\mathrm{TiO}_{2}$ anatase [18-20], a $\mathrm{TiO}_{2}$ rutile- $\mathrm{ZrO}_{2}$ mixture [21], 


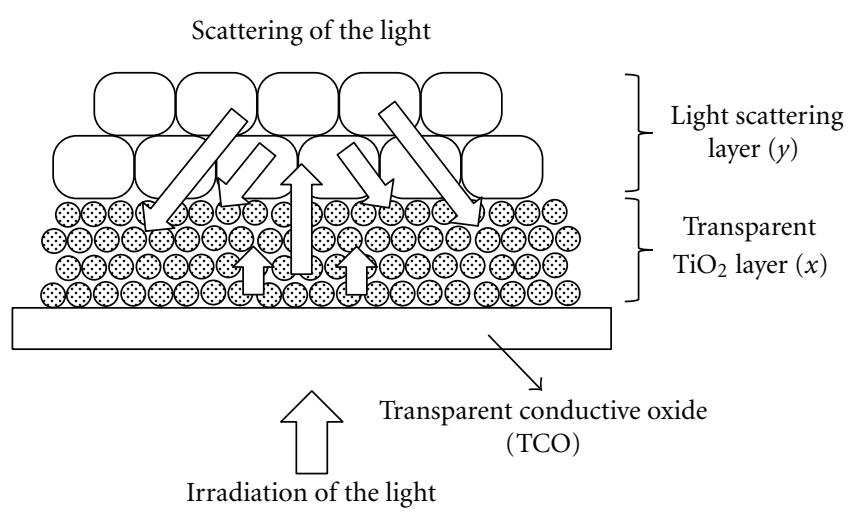

FIGURE 1: The schematic structure of a conventional photoelectrode using the light-scattering effect.

submicrometer-sized mesoporous $\mathrm{TiO}_{2}$ beads [22], hollow sphere $\mathrm{TiO}_{2}$ [23], light-scattering spherical voids [24], and mesoporous $\mathrm{TiO}_{2}$ with quasi-hexagonal and lamellar pore structures $[25,26]$. Additionally, there are many commercial products used to accomplish the light-scattering effect, such as $\mathrm{TiO}_{2}$ - anatase (Fluka), $\mathrm{TiO}_{2}$-rutile (Bayer), and $\mathrm{TiO}_{2}$ anatase (CCIC, Japan) [27].

Figure 1 shows the schematic structure of a conventional photoelectrode using the light-scattering effect. It consists of two layers: a transparent $\mathrm{TiO}_{2}$ layer (TL) using small particles and a light-scattering layer (LSL) using large particles. The light passing through the TL is then scattered by the LSL; this scattered light can then be reabsorbed by the dye molecules in the TL. The light-scattering ability depends on various parameters such as particle size, morphology of the LSL [19], and the thickness of $\mathrm{TiO}_{2}$ photoelectrode [16]. It is important to optimize these parameters in order to maximize the light-scattering effect, resulting in the improvement of the DSC performance. Therefore, many research groups have analyzed the influences that these parameters have on the DSC performance in order to determine the optimal conditions [18-21, 28-31]. As a result, it has been demonstrated that $\mathrm{TiO}_{2}$ with particle sizes between $100 \mathrm{~nm}$ and $400 \mathrm{~nm}$ is advantageous in strengthening the light-scattering effect. In addition, it has been concluded that the light-scattering effect is more effective as the thickness of the TL becomes thinner [21]. However, most studies regarding the influence of the $\mathrm{TiO}_{2}$ thickness on the light-scattering effect have only focused on the thickness of the TL (denoted as " $x$ " in Figure 1) $[18,19,21,30,31]$. To the best of our knowledge, there have been no studies regarding the light-scattering effect according to the thickness of the LSL (denoted as " $y$ " in the Figure 1), although it is related to the length of the optical path of the light.

Therefore, in this study, we report upon a study regarding the light-scattering effect according to the thickness of the LSL. We fabricated the $\mathrm{TiO}_{2}$ photoelectrodes, which have the TL at a fixed thickness and the LSL using various thicknesses, enabling us to investigate the effect of the thickness of the LSL on the photovoltaic performance of the DSC. To confirm this effect, the optical characteristics of the fabricated $\mathrm{TiO}_{2}$ photoelectrodes were analyzed and the performances of the fabricated DSCs were investigated.

\section{Experiments}

2.1. The Fabrication of the $\mathrm{TiO}_{2}$ Photoelectrode. Two kinds of commercial $\mathrm{TiO}_{2}$ paste were used to prepare the photoelectrode possessing the $\mathrm{TL}$ and the LSL. $\mathrm{TiO}_{2}$ paste A, containing small $10 \mathrm{~nm}$ particles (Ti-Nanoxide HT/SP, Solaronix, Switzerland) was used to fabricate the TL. And $\mathrm{TiO}_{2}$ paste $\mathrm{B}$ containing large $400 \mathrm{~nm}$ particles (PST-400C, CCIC, Japan) was used to fabricate the LSL. The fluorinedoped tin oxide (FTO, $13 \Omega /$ sq, Hartford Glass Co. Inc, USA) substrates were prepared by rinsing with acetone, ethanol, and distilled water in an ultrasonic bath in order to remove the contaminants. After that, paste A was deposited on the FTO substrate using the doctor blade method to fabricate the TL. A nanoporous $\mathrm{TiO}_{2}$ was implemented using the sintering process at $450^{\circ} \mathrm{C}$ for $30 \mathrm{~min}$. Paste $\mathrm{B}$ was then deposited over the TL using the doctor blade method in order to add the LSL. The $\mathrm{TiO}_{2}$ photoelectrode was completed using additional sintering process at $450^{\circ} \mathrm{C}$ for $30 \mathrm{~min}$. The thickness of the LSL was controlled by adding the number of the coating and the sintering processes.

Figure 2 shows the morphologies of the TL and the LSL measured using field emission scanning electron microscopy (FE-SEM, S-4200, Hitachi, Japan) operated at $15 \mathrm{kV}$. As shown in Figure 2, the transparent $\mathrm{TiO}_{2}$ film formed a uniform nanoporous structure, which is advantageous in attaching dye molecules. On the other hand, the LSL was composed of polyhedral submicron particles surrounded by nanoparticles. These submicron particles are sufficient to serve as light-scattering centers because their sizes are roughly $350 \sim 450 \mathrm{~nm}$, which are suitable for the lightscattering effect. Table 1 shows the thicknesses of the TL and the LSL, which were measured using a surface profiler (ET 4000, Dong-Il Techno Co. Ltd, Korea). As illustrated in Table 1, the thickness of the TL was fixed at $8 \pm 0.4 \mu \mathrm{m}$, whereas the thicknesses of the LSLs were as $5 \pm 0.2 \mu \mathrm{m}, 9 \pm$ $0.3 \mu \mathrm{m}$, and $13 \pm 0.3 \mu \mathrm{m}$. The increase of the thickness of the LSL was controlled at approximately $4 \mu \mathrm{m}$ steps by adding one coating and one sintering process. Figure 3 illustrates cross-sectional FE-SEM images of prepared $\mathrm{TiO}_{2}$ films: (a) conventional, (b) LS1, (c) LS2, and (d) LS3. As shown Figure 3 , the thickness of the TL was approximately $8.37 \mu \mathrm{m}$, while the thicknesses of the LSLs were as $4.88 \mu \mathrm{m}, 9.07 \mu \mathrm{m}$, and $13.25 \mu \mathrm{m}$, respectively. These might well coincide with the thicknesses of the TL and LSL, which were measured using a surface profiler. It was also confirmed that the thickness of the LSL is increased by adding one coating and one sintering process and the TL and LSL are deposited uniformly without any structural damages.

The fabricated photoelectrodes were soaked in a $0.2 \mathrm{mM}$ N719 dye (cis-bis (isothiocyanato) bis (2,2' -bipyridyl-4,4' discarboxylato)—ruthenium(II) — bis tertabutyl—ammonium, $\mathrm{RuC}_{58} \mathrm{H}_{86} \mathrm{~N}_{8} \mathrm{O}_{8} \mathrm{~S}_{2}$ ) solution for $24 \mathrm{~h}$ at room temperature in order to attach the dye molecules to the $\mathrm{TiO}_{2}$ nanostructure. The dye-adsorbed photoelectrodes were then 
TABLE 1: The thickness of the TL and the LSL measured by the surface profiler.

\begin{tabular}{lccc}
\hline Samples & Transparent $\mathrm{TiO}_{2}$ layer $(x, \mu \mathrm{m})$ & Light-scattering layer $(y, \mu \mathrm{m})$ & Total thickness $(\mu \mathrm{m})$ \\
\hline Conventional (without light-scattering layer) & $8 \pm 0.4$ & - & $8 \pm 0.4$ \\
LS1 (one doctor blade + one sintering) & $8 \pm 0.4$ & $5 \pm 0.2$ & $13 \pm 0.6$ \\
LS2 (two doctor blade + two sintering) & $8 \pm 0.4$ & $9 \pm 0.3$ & $17 \pm 0.7$ \\
LS3 (three doctor blade + three sintering) & $8 \pm 0.4$ & $13 \pm 0.3$ & $21 \pm 0.7$ \\
\hline
\end{tabular}

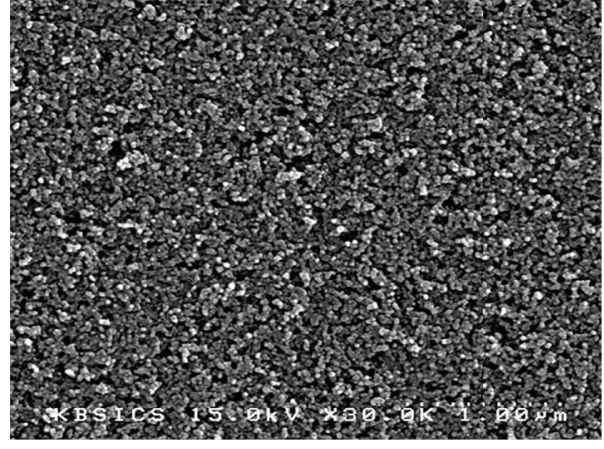

(a)

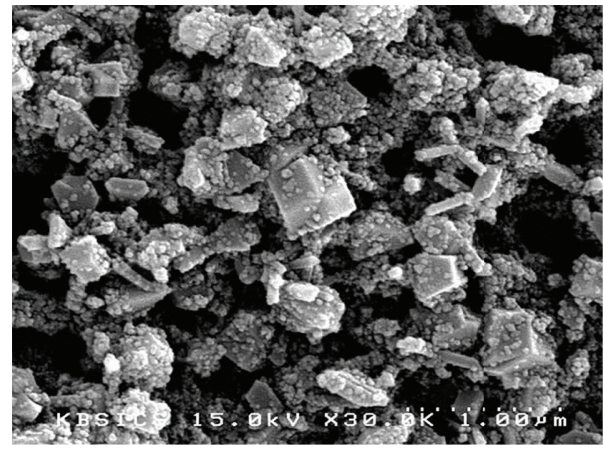

(b)

FIgure 2: The morphologies of (a) the TL (Ti-Nanoxide HT/SP) and (b) the LSL (PST-400C) measured by the FE-SEM.

taken out and rinsed in $99.9 \%$ ethanol $\left(\mathrm{C}_{2} \mathrm{H}_{5} \mathrm{OH}\right)$ in order to remove the excess dye molecules.

\subsection{The Fabrication of Counter Electrode and the DSC} Assembly. The predrilled FTO substrates for the counter electrode were rinsed using same processes as the case of the photoelectrode. In order to fabricate the Pt catalytic layer for the redox process on the counter electrode, a commercial Pt paste (Platisol T/SP, Solaronix, Switzerland) containing a chemical Pt precursor was deposited onto the cleaned substrate using the doctor blade method. The platinized counter electrodes were then sintered at $450^{\circ} \mathrm{C}$ for $10 \mathrm{~min}$. The fabricated photo- and counter electrodes were sealed using a $60 \mu \mathrm{m}$ thermoplast hot-melt sealing sheet (SX 117060, Solaronix, Switzerland). The DSC was completed by injecting a redox electrolyte consisting of $0.5 \mathrm{M} \mathrm{LiI}, 0.05 \mathrm{M}$ $\mathrm{I}_{2}$ and $0.5 \mathrm{M} 4$-tertbutylpyridine in acetonitrile through the predrilled holes in the counter electrode.

2.3. Characterization. In order to analyze the light-scattering effect according to the thickness of the LSL, the reflectance and transmittance spectra of the dye-adsorbed LSLs with different thicknesses were measured by using a UV-Vis spectrophotometer (Cary 300, Varian Inc., USA) equipped with the diffuse reflectance accessory at the wavelengths ranging from $400 \mathrm{~nm}$ to $800 \mathrm{~nm}$. In addition, the amounts of dyeloading to each $\mathrm{TiO}_{2}$ photoelectrode were compared through a dye-desorption experiment to ascertain the changes in the amount of dye-loading in regards to the increase of the LSL thickness. It was calculated after the dye molecules were detached from the $\mathrm{TiO}_{2}$ photoelectrode in a $10 \mathrm{mM} \mathrm{NaOH}$ aqueous solution.
The photovoltaic performances of the DSCs according to the thickness variations of the LSL were measured under 1 sun illumination (air mass $1.5,100 \mathrm{~mW} / \mathrm{cm}^{2}$ ) using a source meter (Model 2400, Keithly Instrument Inc., USA). The active area of the DSC was $0.25 \mathrm{~cm}^{2}$ and the $I-V$ characteristics were determined using the open circuit voltage $\left(V_{\mathrm{OC}}\right)$, the current density $\left(J_{\mathrm{SC}}\right)$, the fill factor $(\mathrm{FF})$ and the conversion efficiency $(\eta)$. The incident photonto-current conversion efficiency (IPCE) was measured as a function of wavelength from $400 \mathrm{~nm}$ to $800 \mathrm{~nm}$ under monochromatic irradiation, emitted from a Xe-lamp (MAX302, Asahi Spectra Co. Ltd, Japan) in order to determine the DSC performance. Open-circuit photovoltage decays (OCVD) experiments were conducted in order to determine how the electron transport and recombination were affected by the LSL thickness. In this experiment, light was irradiated onto the DSC until the $V_{\text {OC }}$ was steady, and then, the irradiation was halted. The applied voltage decay was recorded using a potentiostat/galvanostat (SP-50, BioLogic Science Instruments, France) from the full darkness point.

\section{Results and Discussion}

3.1. The Light-Scattering Effect according to the LSL Thickness. Figure 4 shows the reflectance spectra of the dyeadsorbed LSL on the TL according to the thicknesses. As shown in Figure 4, the reflectance is drastically increased at wavelengths above $550 \mathrm{~nm}$. This means that the lightscattering effect is improved by introducing the LSL on the TL. The reflectance is similar at wavelengths ranging between $550 \mathrm{~nm}$ and $600 \mathrm{~nm}$, irrespective of the variation of LSL thickness. On the other hand, the reflectance increases along with the increase of the LSL thickness from 5 $\pm 0.2 \mu \mathrm{m}$ to $9 \pm 0.3 \mu \mathrm{m}$ at wavelengths above $600 \mathrm{~nm}$. 


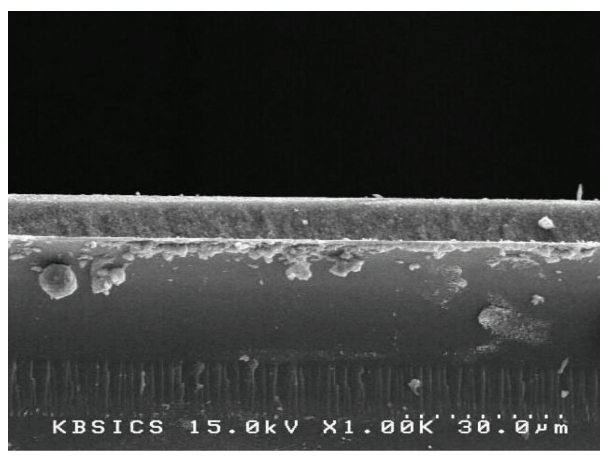

(a)

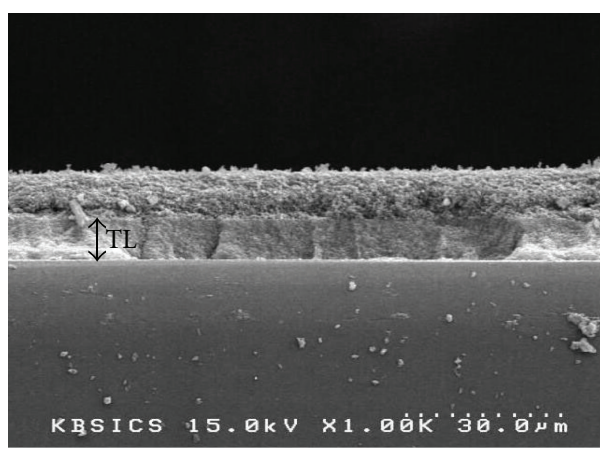

(c)

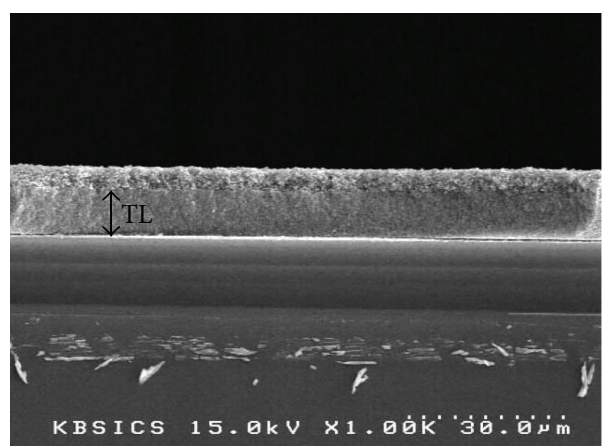

(b)

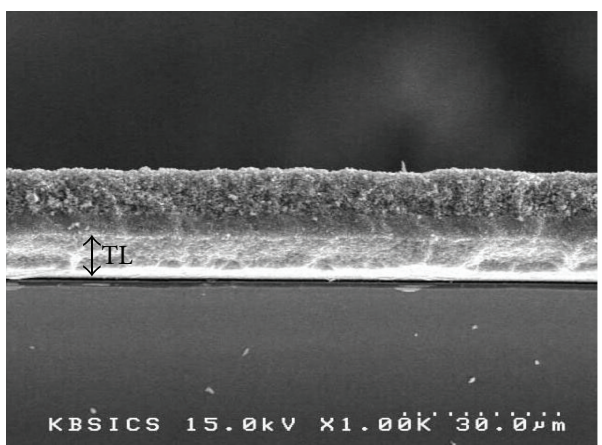

(d)

FIgure 3: Cross-sectional FE-SEM images of prepared $\mathrm{TiO}_{2}$ films: (a) conventional, (b) LS1, (c) LS2, and (d) LS3.

This indicates that more irradiated light to the LSL is reflected by further thicker LSL. Figure 5 illustrates the transmittance spectra of the dye-adsorbed LSL on the TL according to the thickness. The transmittance is slightly decreased by increasing the LSL thickness from $5 \pm 0.2 \mu \mathrm{m}$ to $9 \pm 0.3 \mu \mathrm{m}$ in the region above $600 \mathrm{~nm}$, while it is also similar in the region until $600 \mathrm{~nm}$. However, the reflectance and transmittance are almost not changed by the LSL thickness, when LSL thickness is increased from $9 \pm 0.3 \mu \mathrm{m}$ to $13 \pm$ $0.3 \mu \mathrm{m}$.

Figure 6 represents the sum of the reflectance and transmittance of dye-adsorbed LSL on the TL according to the thicknesses, obtained from the Figures 4 and 5 . The tendency of spectra is very similar to the reflectance, because the transmittance is slightly changed, compared to the reflectance. The sum of the reflectance and transmittance is similar at the wavelengths between $400 \mathrm{~nm}$ and $680 \mathrm{~nm}$, while it is increased in the region above $680 \mathrm{~nm}$ by increasing the LSL thickness from $5 \pm 0.2 \mu \mathrm{m}$ to $9 \pm 0.3 \mu \mathrm{m}$. On the other hand, it is not increased in the region above $680 \mathrm{~nm}$ along with the increase of the LSL thickness from $9 \pm$ $0.3 \mu \mathrm{m}$ to $13 \pm 0.3 \mu \mathrm{m}$. From these results, it is confirmed that the variation of the LSL thickness affects the lightscattering effect in the long wavelength region above $680 \mathrm{~nm}$. The light-scattering effect is improved by increasing the LSL thickness until $9 \pm 0.3 \mu \mathrm{m}$, because the further thicker LSL provides more chance to scatter the light. However, the further thick LSL above $9 \pm 0.3 \mu \mathrm{m}$ is not significant to

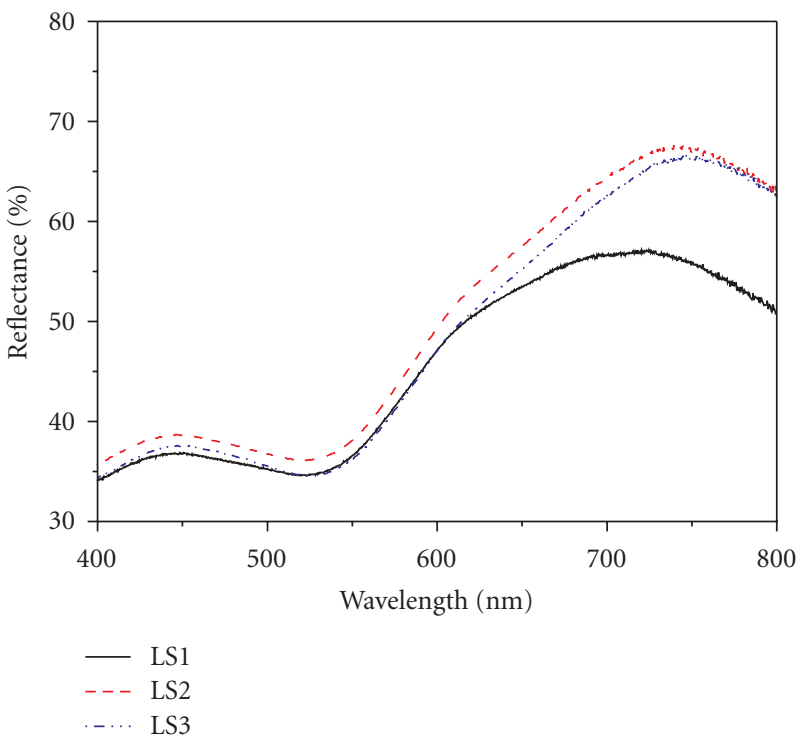

FIgURE 4: The reflectance spectra of the dye-adsorbed LSL on the TL according to the LSL thicknesses.

improve the light-scattering effect, because it is estimated that the light-scattering mostly occurs at the front part in the LSL. Therefore, the light-scattering effect is improved along with increase of the LSL thickness to around $9 \mu \mathrm{m}$, while it is saturated above the LSL thickness of approximately $9 \mu \mathrm{m}$. 


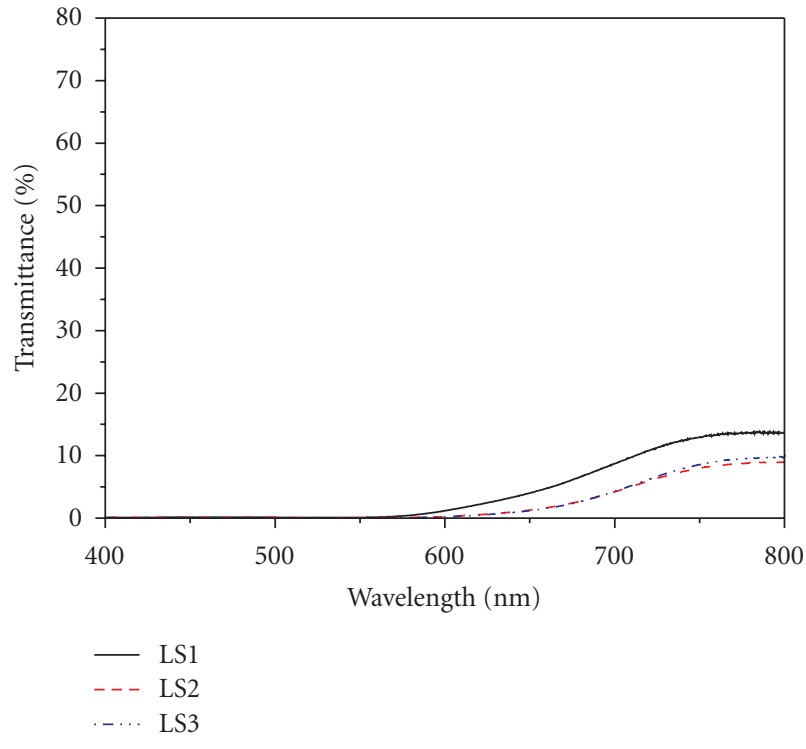

FIGURE 5: The transmittance spectra of the dye-adsorbed LSL on the TL according to the LSL thicknesses.

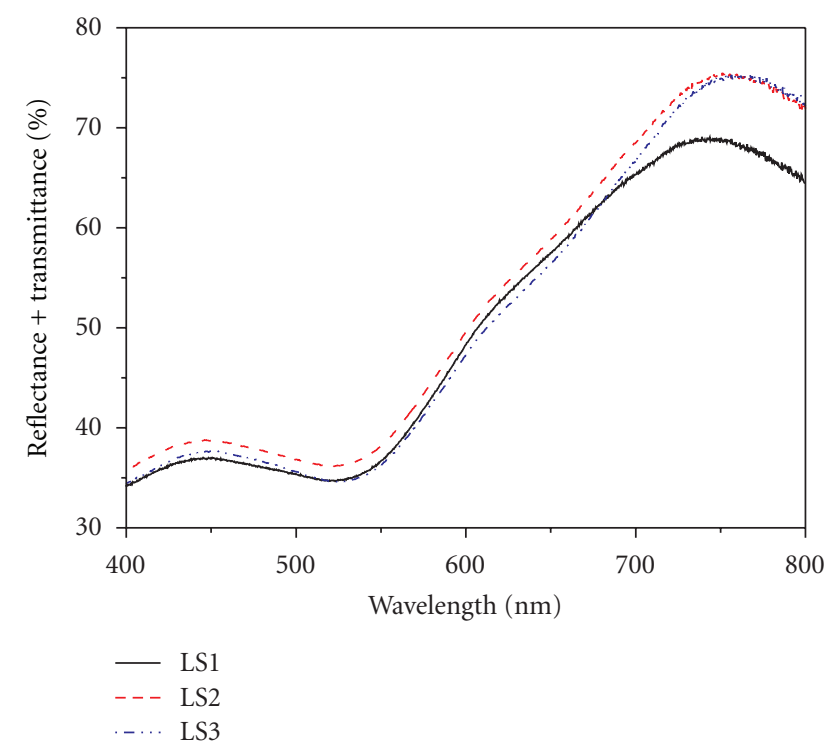

Figure 6: The sum of the reflectance and transmittance of dyeadsorbed LSL on the TL according to the thicknesses.

3.2. The Performance of the DSC according to the LSL Thickness. Table 2 shows the performances and the dyeloading amounts of the DSCs in regards to the changes in the LSL thicknesses. As illustrated in Table 2, the conversion efficiency of the DSC is improved, as a result the increase in $J_{S C}$ when the thickness of the LSL increases to the thickness of approximately $9 \mu \mathrm{m}$. This is caused by the enhancement of the light-scattering effect with the increase of the thickness of the LSL. An additional factor is the increase of the dye-loading with the increase in the thickness of the LSL, as shown in Table 2. It is caused by the $\mathrm{TiO}_{2}$ nanoparticles surrounding to the polyhedral shaped-lightscattering centers in the LSL, which is advantageous to attach more dye molecules to the $\mathrm{TiO}_{2}$ photo-electrode (Figure 2(b)).

However, the efficiency decreases when the thickness of the LSL is $13 \pm 0.3 \mu \mathrm{m}$, even though the light-scattering effect is the same as that for the thickness of $9 \pm 0.3 \mu \mathrm{m}$ and the dye-loading is increased. It is thought that this is caused by the electron recombination, resulting from the increase of the thickness of the $\mathrm{TiO}_{2}$ photoelectrode along with the increase in the thickness of the LSL. Generally, the $V_{\mathrm{OC}}$ is related to the electron recombination in the DSC; it decreases when the electron recombination loss is strengthened at the $\mathrm{TiO}_{2}$ /electrolyte interface [27]. The $V_{\mathrm{OC}}$ decreases when the thickness of the LSL increases (Table 2). This means that the electron recombination becomes more active with an increase in the thickness of the $\mathrm{TiO}_{2}$ photoelectrode. This is clearly proved by the OCVD experiment. Figure 7 shows the decays of the $V_{\mathrm{OC}}$ depending on the thickness of the LSL. In the OCVD experiment, the response time is determined by the reciprocal of the derivative of the decay curve normalized by the $V_{\text {OC }}$, expressed as

$$
\tau=-\left(\frac{k_{B} T}{e}\right) \cdot\left(\frac{d V_{\mathrm{OC}}}{d t}\right)^{-1}
$$

where $k_{B}$ is the Boltzmann's constant, $T$ is the temperature, and $e$ is the elementary charge. The response time $(\tau)$ is equal to the electron lifetime, which is related to the recombination process [32-34]. From this equation, it is known that rapid decay of the $V_{\mathrm{OC}}$ means the short electron lifetime. And it indicates that the electron recombination is more active at the $\mathrm{TiO}_{2}$ /electrolyte interface. As shown in Figure 6 , the $V_{\text {OC }}$ decay speed increases, as the thickness of the LSL increases. The electron recombination becomes active according to the increase in the LSL thickness, because the increase in the thickness of the LSL provides more opportunities for electrons to recombine with the electrolyte during the electron transport process. And it is also caused by the hindrance of the electrolyte diffusion due to the increase of the LSL thickness. The hindered electrolyte diffusion provides insufficient charge carriers, resulting in more electron recombination. In addition to the decrease of the $V_{\mathrm{OC}}$, this also verifies the enhancement of the electron recombination with the enlargement of the $\mathrm{TiO}_{2}$ photoelectrode thickness, resulting from the increase of the thickness of the LSL.

Figure 8 shows the IPCE spectra of a conventional DSC without an LSL and the DSCs with the different LSLs thicknesses. The IPCE is determined by

$$
\operatorname{IPCE}(\lambda)=\operatorname{LHE}(\lambda) \Phi_{e-\mathrm{inj}}(\lambda) \eta_{\mathrm{CC}}(\lambda),
$$

where $\operatorname{LHE}(\lambda)$ is the light-harvesting efficiency, $\Phi_{e-\text { inj }}(\lambda)$ is the electron injection yield from the dye excited state into the $\mathrm{TiO}_{2}$, and $\eta_{\mathrm{CC}}(\lambda)$ is the charge collection efficiency at the transparent conductive oxide electrodes [35]. As illustrated in Figure 8, the IPCE of the DSCs with the LSLs is higher than that of the conventional DSC and it is improved, as the thickness of the LSL increased. This is mainly caused by 
TABLE 2: The performances and the dye-loading amounts in the DSCs with the changes in the thickness of the LSLs.

\begin{tabular}{lccccc}
\hline Samples & $V_{\mathrm{OC}}(\mathrm{V})$ & $J_{\mathrm{SC}}\left(\mathrm{mA} / \mathrm{cm}^{2}\right)$ & $\mathrm{FF}$ & $\eta(\%)$ & Amount of dye loading $\left(\mathrm{mol} / \mathrm{cm}^{2}\right)$ \\
\hline Conventional & 0.773 & 9.677 & 0.70 & 5.24 & $2.011 \times 10^{-5}$ \\
LS1 & 0.769 & 14.545 & 0.61 & 6.82 & $2.369 \times 10^{-5}$ \\
LS2 & 0.763 & 17.533 & 0.61 & 8.16 & $2.454 \times 10^{-5}$ \\
LS3 & 0.757 & 15.966 & 0.62 & 7.49 & $2.744 \times 10^{-5}$ \\
\hline
\end{tabular}

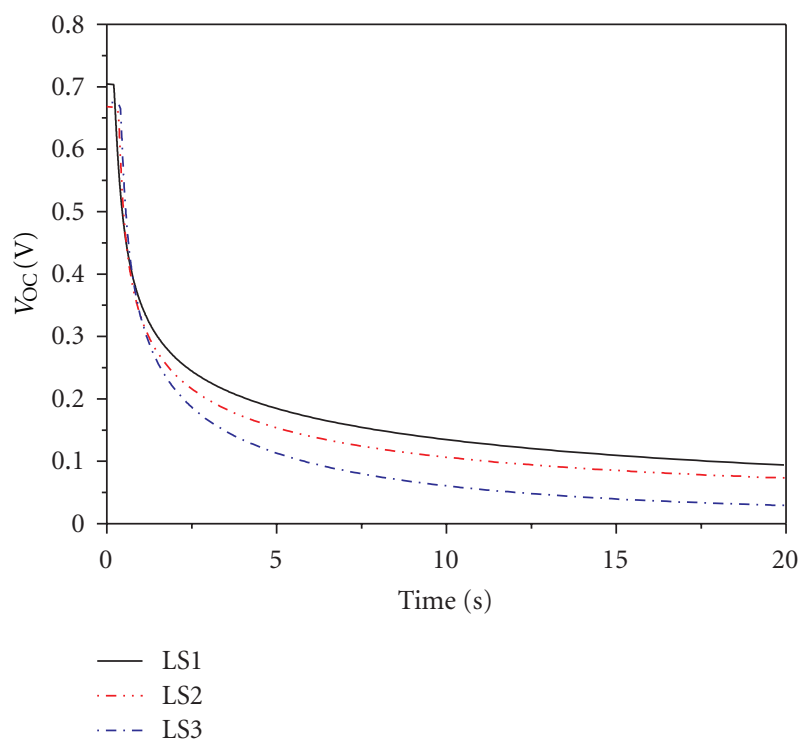

FIgURE 7: The $V_{\mathrm{OC}}$ decay according to the thickness of the LSL.

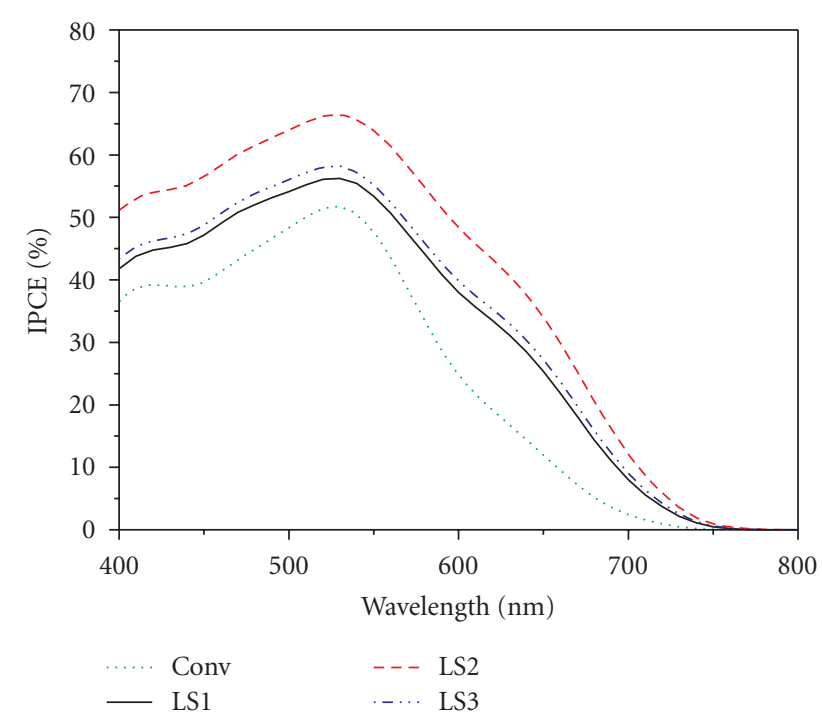

FIGURE 8: The IPCE spectra of the conventional DSC without the LSL and the DSCs with the different thickness LSLs.

the improvement in the light-harvesting efficiency, resulting from the enhanced light-scattering effect and the increase in the dye-loading. The IPCE is improved by the increase of the dye-loading with the increase in the thickness of the LSL at the wavelengths between $400 \mathrm{~nm}$ and $600 \mathrm{~nm}$.
The improvement of the IPCE at the wavelengths between $600 \mathrm{~nm}$ and $700 \mathrm{~nm}$ is caused not only by the increase in the dye loading but also by the enhancement of the light-scattering effect. At the wavelengths above $700 \mathrm{~nm}$, the enhancement of the light-scattering effect with the increase of the thickness of the LSL is the dominant factor that influences the improvement of the IPCE. However, in the case of the LS3, the IPCE decreases irrespective of the increase in the LSL thickness. This is caused by the decrease of the charge collection efficiency, resulting from the greater electron recombination in accordance with the increase in the thickness of the LSL.

In summary, the light-scattering effect is improved when the thickness of the LSL is increased, but saturates at thicknesses above $9 \pm 0.3 \mu \mathrm{m}$. The increase in the thickness of the LSL assists the attachment of more dye molecules, but is disadvantageous in the transport of electrons in the DSC due to increased electron recombination. Consequently, it is confirmed that the increase of the LSL thickness to some degree is beneficial to improve the light-scattering effect at long wavelength region, while the further thick LSL is not significant to improve the light-scattering effect. On the contrary, the further thick LSL causes the decreased performance of the DSC by inducing more electron recombination.

\section{Conclusion}

In this study, we analyzed the light-scattering effect according to the LSL thickness on the performance of the DSC. The increase in the thickness of the LSL induces the improvement of the DSC performance by enhancing the light-scattering effect in the long-wave region and by increasing the dyeloading. However, an excessively thick LSL has a negative influence on the electron transport in the $\mathrm{TiO}_{2}$ photoelectrode due to the electron recombination despite the improved light-scattering effect and dye-loading. As a result, it was demonstrated that the increase of the LSL thickness to some degree is advantageous to improve the light-scattering effect, while the further thick LSL is not a crucial condition to improve the light-scattering effect. It is thought that this result will be a great positive factor in setting the standard conditions of the LSL for highly efficient DSC in the commercial DSC fabrication process.

\section{Acknowledgment}

This work was supported by National Research Foundation of Korea (NRF) grant funded by the Korea government (MEST) (no. 20110001295). 


\section{References}

[1] B. O’Regan and M. Grätzel, "A low-cost, high-efficiency solar cell based on dye-sensitized colloidal $\mathrm{TiO}_{2}$ films," Nature, vol. 353, no. 6346, pp. 737-740, 1991.

[2] M. Gratzel, "Perspective for dye-sensitized nanocrystalline solar cells," Progress in Photovoltaics: Research and Applications, vol. 8, pp. 171-185, 2000.

[3] M. Grätzel, "Conversion of sunlight to electric power by nanocrystalline dye-sensitized solar cells," Journal of Photochemistry and Photobiology A, vol. 164, no. 1-3, pp. 3-14, 2004.

[4] K. Kalyanasundaram, Dye-Sensitized Solar Cells, EPFL Press, Lausanne, Switzerland, 1st edition, 2010.

[5] M. Grätzel, "Solar energy conversion by dye-sensitized photovoltaic cells," Inorganic Chemistry, vol. 44, no. 20, pp. 6841$6851,2005$.

[6] M. Gratzel, "Dye-sensitized solar cells," Journal of Photochemistry and Photobiology C, vol. 4, pp. 145-153, 2003.

[7] A. S. Polo, M. K. Itokazu, and N. Y. Murakami Iha, "Metal complex sensitizers in dye-sensitized solar cells," Coordination Chemistry Reviews, vol. 248, no. 13-14, pp. 1343-1361, 2004.

[8] H. Qin, S. Wenger, M. Xu et al., "An organic sensitizer with a fused dithienothiophene unit for efficient and stable dyesensitized solar cells," Journal of the American Chemical Society, vol. 130, no. 29, pp. 9202-9203, 2008.

[9] S. Rani, P. K. Shishodia, and R. M. Mehra, "Development of a dye with broadband absorbance in visible spectrum for an efficient dye-sensitized solar cell," Journal of Renewable and Sustainable Energy, vol. 2, no. 4, Article ID 043103, 2010.

[10] A. Yella, H. W. Lee, H. N. Tsao et al., "Porphyrine-sensitized solar cells with cobalt (II/III)-based redox electrolyte exceed 12 percent efficiency," Science, vol. 334, no. 6056, pp. 629-634, 2011.

[11] M. Dürr, A. Bamedi, A. Yasuda, and G. Nelles, "Tandem dye-sensitized solar cell for improved power conversion efficiencies," Applied Physics Letters, vol. 84, no. 17, pp. 33973399, 2004.

[12] W. Kubo, A. Sakamoto, T. Kitamura, Y. Wada, and S. Yanagida, "Dye-sensitized solar cells: improvement of spectral response by tandem structure," Journal of Photochemistry and Photobiology A, vol. 164, no. 1-3, pp. 33-39, 2004.

[13] M. Murayama and T. Mori, "Dye-sensitized solar cell using novel tandem cell structure," Journal of Physics D, vol. 40, no. 6, pp. 1664-1668, 2007.

[14] A. Usami, "Theoretical study of application of multiple scattering of light to a dye-sensitized nanocrystalline photoelectrochemical cell," Chemical Physics Letters, vol. 277, no. 13, pp. 105-108, 1997.

[15] J. Ferber and J. Luther, "Computer simulations of light scattering and absorption in dye-sensitized solar cells," Solar Energy Materials and Solar Cells, vol. 54, no. 1-4, pp. 265-275, 1998.

[16] A. Usami, "Theoretical simulations of optical confinement in dye-sensitized nanocrystalline solar cells," Solar Energy Materials and Solar Cells, vol. 64, no. 1, pp. 73-83, 2000.

[17] G. Rothenberger, P. Comte, and M. Grätzel, "Contribution to the optical design of dye-sensitized nanocrystalline solar cells," Solar Energy Materials and Solar Cells, vol. 58, no. 3, pp. 321336, 1999.

[18] Z. S. Wang, H. Kawauchi, T. Kashima, and H. Arakawa, "Significant influence of $\mathrm{TiO}_{2}$ photoelectrode morphology on the energy conversion efficiency of N719 dye-sensitized solar cell," Coordination Chemistry Reviews, vol. 248, no. 13-14, pp. 13811389, 2004.
[19] H. J. Koo, J. Park, B. Yoo, K. Yoo, K. Kim, and N. G. Park, "Size-dependent scattering efficiency in dye-sensitized solar cell,” Inorganica Chimica Acta, vol. 361, no. 3, pp. 677-683, 2008.

[20] S. H. Kang, J. Y. Kim, H. S. Kim, H. D. Koh, J. S. Lee, and Y. E. Sung, "Influence of light scattering particles in the $\mathrm{TiO}_{2}$ photoelectrode for solid-state dye-sensitized solar cell," Journal of Photochemistry and Photobiology A, vol. 200, no. 23, pp. 294-300, 2008.

[21] S. Hore, C. Vetter, R. Kern, H. Smit, and A. Hinsch, "Influence of scattering layers on efficiency of dye-sensitized solar cells," Solar Energy Materials and Solar Cells, vol. 90, no. 9, pp. 11761188, 2006.

[22] F. Huang, D. Chen, X. L. Zhang, R. A. Caruso, and Y. B. Cheng, "Dual-function scattering layer of submicrometersized mesoporous $\mathrm{TiO}_{2}$ beads for high-efficiency dyesensitized solar cells," Advanced Functional Materials, vol. 20, no. 8, pp. 1301-1305, 2010.

[23] J. Yu, Q. Li, and Z. Shu, "Dye-sensitized solar cells based on double-layered $\mathrm{TiO}_{2}$ composite films and enhanced photovoltaic performance," Electrochimica Acta, vol. 56, no. 18, pp. 6293-6298, 2011.

[24] S. Hore, P. Nitz, C. Vetter, C. Prahl, M. Niggemann, and R. Kern, "Scattering spherical voids in nanocrystalline $\mathrm{TiO}_{2}-$ enhancement of efficiency in dye-sensitized solar cells," Chemical Communications, no. 15, pp. 2011-2013, 2005.

[25] M. J. Q. Yong, A. S. W. Wong, and G. W. Ho, "Mesophase ordering and macroscopic morphology structuring of mesoporous $\mathrm{TiO}_{2}$ film," Materials Chemistry and Physics, vol. 116, no. 2-3, pp. 563-568, 2009.

[26] S. Agarwala, M. Kevin, A. S. W. Wong, C. K. N. Peh, V. Thavasi, and G. W. Ho, "Mesophase ordering of $\mathrm{TiO}_{2}$ film with high surface area and strong light harvesting for dye-sensitized solar cell," ACS Applied Materials and Interfaces, vol. 2, no. 7, pp. 1844-1850, 2010.

[27] J. M. Kroon, N. J. Bakker, H. J. P. Smit et al., "Nanocrystalline dye-sensitized solar cells having maximum performance," Progress in Photovoltaics: Research and Applications, vol. 15, no. 1, pp. 1-18, 2007.

[28] S. Ngamsinlapasathian, T. Sreethawong, Y. Suzuki, and S. Yoshikawa, "Single- and double-layered mesoporous $\mathrm{TiO}_{2} /$ $\mathrm{P} 25 \mathrm{TiO}_{2}$ electrode for dye-sensitized solar cell," Solar Energy Materials and Solar Cells, vol. 86, no. 2, pp. 269-282, 2005.

[29] K. M. Lee, V. Suryanarayanan, and K. C. Ho, "The influence of surface morphology of $\mathrm{TiO}_{2}$ coating on the performance of dye-sensitized solar cells," Solar Energy Materials and Solar Cells, vol. 90, no. 15, pp. 2398-2404, 2006.

[30] S. Ito, S. M. Zakeeruddin, R. Humphry-Baker et al., "Highefficiency organic-dye-sensitized solar cells controlled by nanocrystalline- $\mathrm{TiO}_{2}$ electrode thickness," Advanced Materials, vol. 18, no. 9, pp. 1202-1205, 2006.

[31] S. Ito, M. K. Nazeeruddin, S. M. Zakeeruddin et al., "Study of dye-sensitized solar cells by scanning electron micrograph observation and thickness optimization of porous $\mathrm{TiO}_{2}$ electrodes," International Journal of Photoenergy, vol. 2009, Article ID 517609, 8 pages, 2009.

[32] A. Zaban, M. Greenshtein, and J. Bisquert, "Determination of the electron lifetime in nanocrystalline dye solar cells by opencircuit voltage decay measurements," ChemPhysChem, vol. 4, no. 8, pp. 859-864, 2003.

[33] J. Bisquert, A. Zaban, M. Greenshtein, and I. Mora-Seró, "Determination of rate constants for charge transfer and the distribution of semiconductor and electrolyte electronic energy levels in dye-sensitized solar cells by open-circuit 
photovoltage decay method," Journal of the American Chemical Society, vol. 126, no. 41, pp. 13550-13559, 2004.

[34] J. Bisquert, F. Fabregat-Santiago, I. Mora-Seró, G. GarciaBelmonte, and S. Giménez, "Electron lifetime in dyesensitized solar cells: theory and interpretation of measurements," Journal of Physical Chemistry C, vol. 113, no. 40, pp. 17278-17290, 2009.

[35] N. Koide, A. Islam, Y. Chiba, and L. Han, "Improvement of efficiency of dye-sensitized solar cells based on analysis of equivalent circuit," Journal of Photochemistry and Photobiology A, vol. 182, no. 3, pp. 296-305, 2006. 


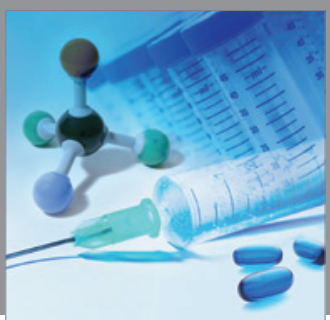

International Journal of

Medicinal Chemistry

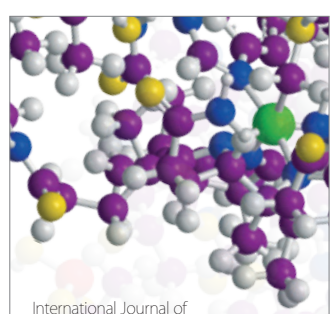

Carbohydrate Chemistry

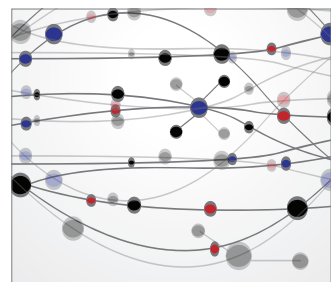

The Scientific World Journal
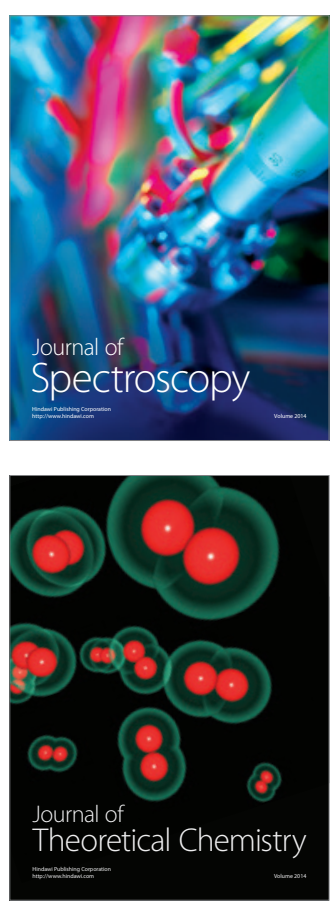
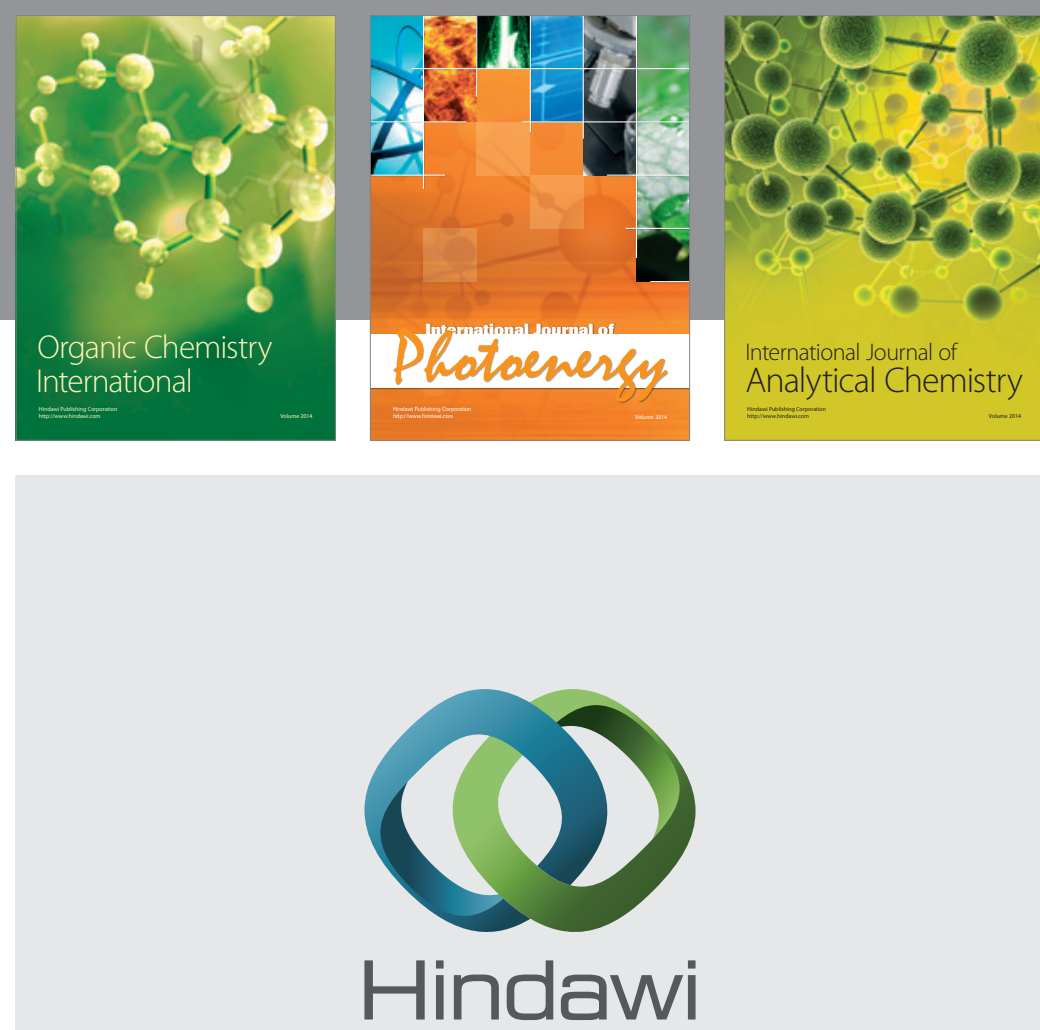

Submit your manuscripts at

http://www.hindawi.com
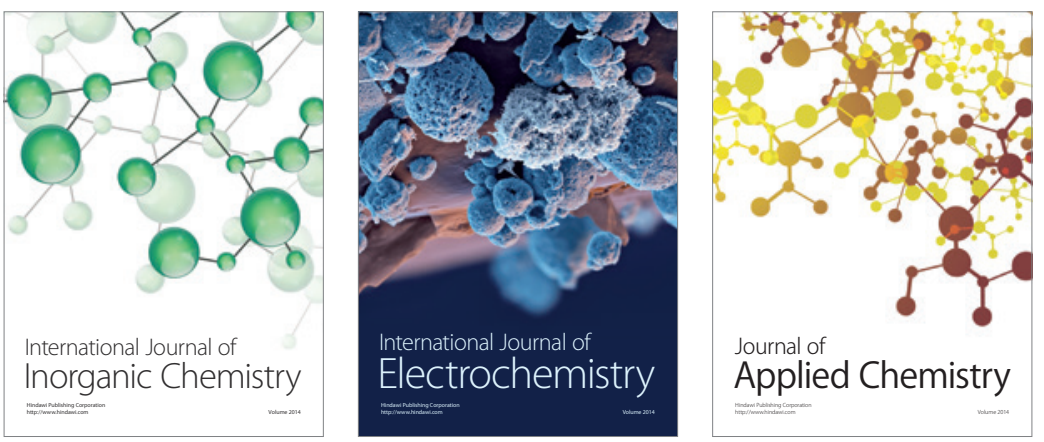

Journal of

Applied Chemistry
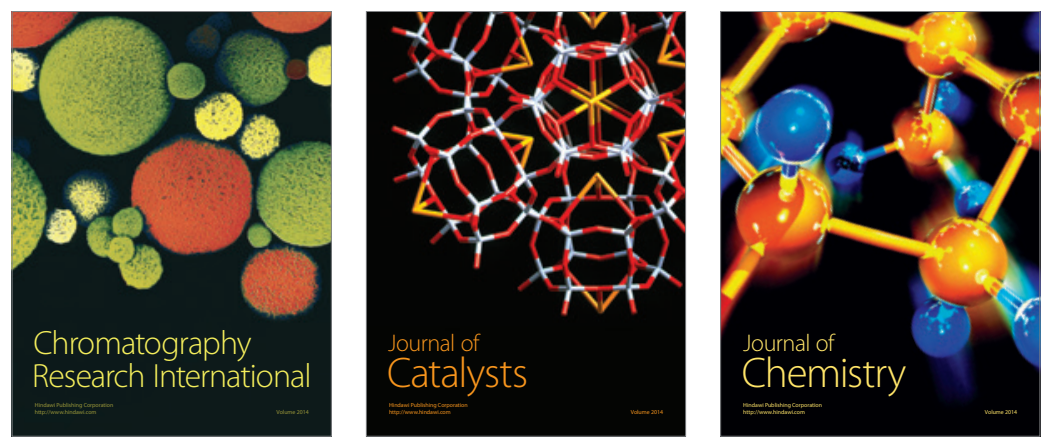
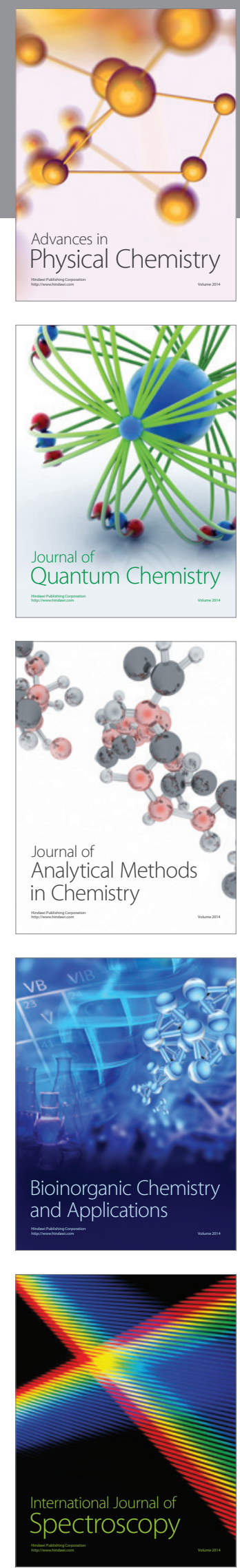